\title{
Macrophage inflammatory protein $3 \alpha$ transgene attracts dendritic cells to established murine tumors and suppresses tumor growth
}

\author{
Toshiaki Fushimi, ${ }^{1}$ Akira Kojima, ${ }^{1}$ Malcolm A.S. Moore, ${ }^{2}$ and Ronald G. Crystal ${ }^{1}$ \\ ${ }^{1}$ Division of Pulmonary and Critical Care Medicine, Weill Medical College of Cornell University, \\ New York Presbyterian Hospital, New York, New York, USA \\ ${ }^{2}$ James Ewing Laboratory of Developmental Hematopoiesis, Memorial Sloan-Kettering Cancer Center, \\ New York, New York, USA \\ Address correspondence to: Ronald G. Crystal, Weill Medical College of Cornell University, New York Presbyterian Hospital, \\ 520 East 70th Street, Suite 505, New York, New York 10021, USA. Phone: (212) 746-2258; Fax: (212) 746-8383; \\ E-mail: geneticmedicine@mail.med.cornell.edu. \\ Received for publication June 10, 1999, and accepted in revised form March 21, 2000.
}

\begin{abstract}
Dendritic cells (DCs) are powerful antigen-presenting cells that function as the principal activators of $\mathrm{T}$ cells. Since the human CC chemokine, macrophage inflammatory protein $3 \alpha$ (MIP-3 $\alpha$ ), is chemotactic for DCs in vitro, we hypothesized that adenovirus-mediated gene transfer of MIP-3 $\alpha$ (AdMIP-3 $\alpha$ ) to tumors might induce local accumulation of DCs and inhibit growth of preexisting tumors. AdMIP$3 \alpha$ directed expression of mRNA and protein in vitro, and the supernatant of A549 cells infected with AdMIP-3 $\alpha$ was chemotactic for DCs. In vivo, injection of AdMIP-3 $\alpha$ into subcutaneous tumors resulted in local expression of the MIP-3 $\alpha$ cDNA and in the local accumulation of DCs. In four syngeneic tumor models, growth of established tumors was significantly inhibited compared with untreated tumors or tumors injected with control vector, and in all but the poorly immunogenic LLC carcinoma model, this treatment increased survival advantage of the preexisting tumors. In all four tumor models, intratumoral injection of AdMIP-3 $\alpha$ induced the local accumulation of CD8b. $2^{+}$cells and elicited tumor-specific cytotoxic T-lymphocyte activity, and adoptive transfer of splenocytes of animals receiving this treatment protected against a subsequent challenge with the identical tumor cells. In wild-type but not in CD8-deficient mice, AdMIP-3 $\alpha$ inhibited the growth of tumors. Finally, AdMIP-3 $\alpha$ also inhibited the growth of distant tumors. This strategy may be useful for enlisting the help of DCs to boost anti-tumor immunity against local and metastatic tumors without the necessity of ex vivo isolation and manipulation of DCs.
\end{abstract}

J. Clin. Invest. 105:1383-1393 (2000).

\section{Introduction}

Dendritic cells (DCs), potent antigen-presenting cells that function as the principal activators of quiescent $\mathrm{T}$ cells to initiate immune responses, reside in bone marrow, blood, organs frequently exposes to antigens, and lymphoid tissues $(1,2)$. After interacting with antigens, immature DCs undergo a maturation process as the cells migrate to lymphoid tissue, where the mature DCs prime naive T cells (1-3). Based on the understanding of the central role of DCs in initiating immune responses, a variety of strategies have been devised to use DCs to stimulate immunity against tumor antigens, including pulsing DCs with tumorrelated peptides or apoptotic tumor cells or genetically modifying DCs with total RNA from tumor cells, genes coding for tumor-related antigens, or genes that activate immune responses (1, 2, 4-34).

Although all of these strategies are effective in suppressing tumor growth in experimental animal models, all require the DCs to be removed from the body, manipulated ex vivo, and returned to the tumor-bearing donor/recipient $(1,2,11,14)$. The present study is directed toward evaluating a new paradigm of harnessing DCs to initiate antitumor immunity by using ex vivo gene transfer to attract endogenous DCs to tumors, thus circumventing the necessity of ex vivo manipulation to bring the DCs and tumor cells/tumor antigens into contact. To achieve this, we have capitalized on the recognition that macrophage inflammatory protein- $3 \alpha$ (MIP-3 $\alpha$ ), a CC chemokine, is a potent chemoattractant for DCs and, thus, likely plays a role in the directional migration of DCs in vivo (35-38). We hypothesized that if tumors could be genetically modified in vivo to produce MIP- $3 \alpha$, the consequences should be accumulation of DCs within the tumor, and the in vivo interaction of DCs with the tumor cells/tumor antigens should induce immunity against the tumor with consequent suppression of tumor growth. To evaluate this concept, we have used an adenovirus (Ad) vector to transfer and express the MIP- $3 \alpha$ cDNA in a variety of preformed murine subcutaneous tumors. The data demonstrate that this strategy does induce local accumulation of DCs, induce tumor-specific cellular immunity, and suppress growth of preexisting tumors. 

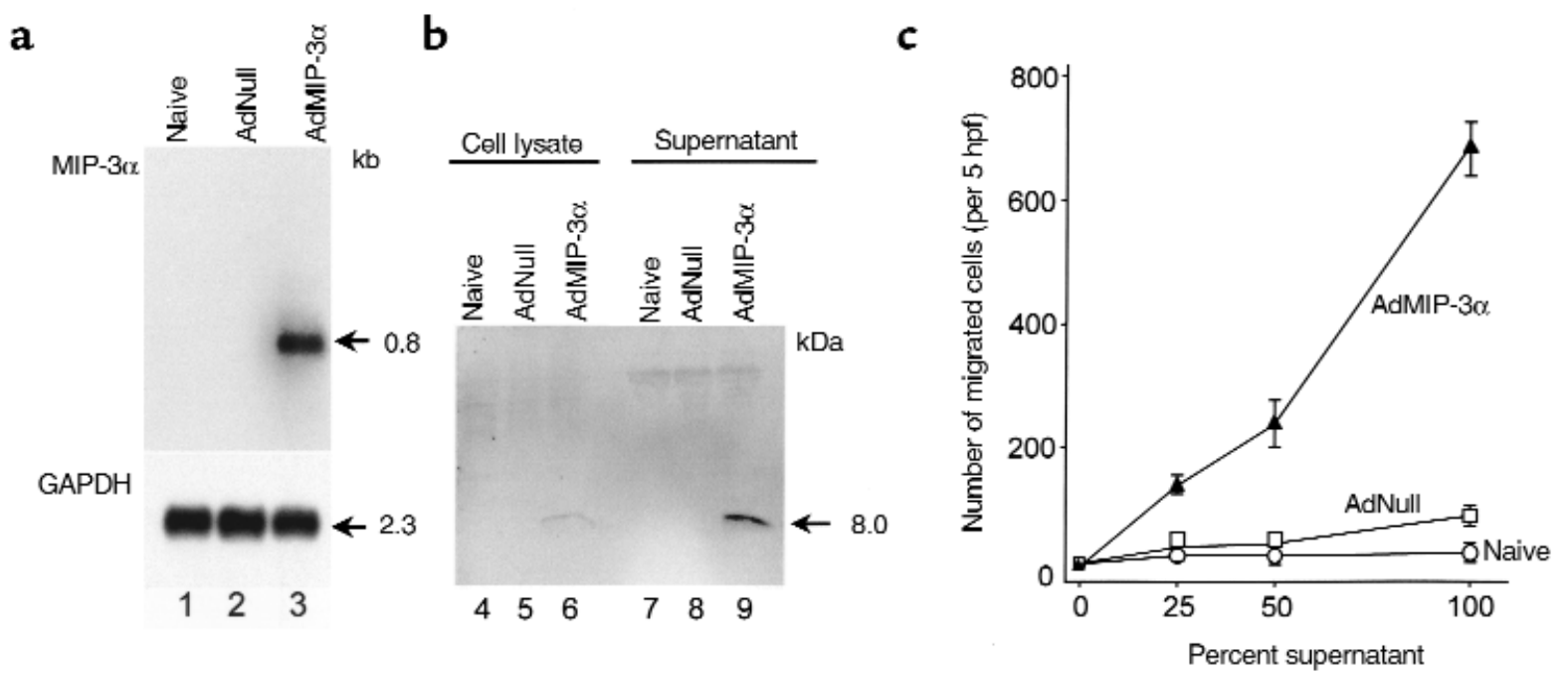

\section{Figure 1}

Function of the AdMIP-3 $\alpha$ vector in vitro. The A549 line was infected with the AdMIP-3 $\alpha$ vector or the control AdNull vector (both, moi 10). (a) Northern analysis. Three days after infection, $10 \mu \mathrm{g}$ RNA per lane was hybridized with a human MIP-3 $\alpha$ probe. Lane 1 , control (naive, uninfected cells); lane 2, AdNull (additional control); and lane 3, AdMIP-3 $\alpha$. GAPDH expression served as an RNA control. The size of the MIP-3 $\alpha$ and GAPDH transcripts are indicated. (b) Western analysis. Cell lysates (lanes 4-6) and supernatants (lanes 7-9) of A549 cells infected with AdMIP-3 $\alpha$ were evaluated after 3 days. The membrane was incubated with an anti-human MIP-3 $\alpha$ antibody, then visualized with a luminol-based chemiluminescent reaction. Lanes 4 and 7, control (naive, uninfected cells); lanes 5 and 8 , AdNull; and lanes 6 and 9, AdMIP-3 $\alpha$. The 8.0-kDa MIP-3 $\alpha$ protein is clearly evident in the supernatant, but very little is present in the lysate. (c) Directed migration of DCs induced by supernatants of A549 cells infected with AdMIP-3 $\alpha$. A suspension of murine DCs was placed in the upper chamber, and supernatants of A549 cells infected for 3 days with AdMIP-3 $\alpha$ or AdNull, or naive, uninfected cells were placed in the lower chamber. After 90 minutes at $37^{\circ} \mathrm{C}$, directed migration was expressed as the number of cells that had migrated to the lower chamber, seen in 5 high power fields. Checkerboard analysis demonstrates that the migration was chemotactic, rather than chemokinetic (see Table 1).

\section{Methods}

Adenovirus vectors. The adenovirus vectors used for this study are based on the Ad5 backbone with deletions of E1 and $\mathrm{E} 3$ and the expression cassette in the $\mathrm{E} 1$ region (39, 40). The AdMIP- $3 \alpha$ vector expresses the human MIP- $3 \alpha$ cDNA under control of the constitutive cytomegalovirus early/immediate promotor/enhancer (41). The AdNull vector, serving as a negative control, is identical to the AdMIP- $3 \alpha$ vector but contains no transgene in the expression cassette (41). The Ad vectors were purified by cesium chloride density gradient ultracentrifugation, titered by plaque-forming assay on 293 cells, and demonstrated to be free of replication competent $\operatorname{Ad}(39,40,42)$.

Mice. Female C57Bl/6 (H-2b), Balb/c (H-2d), and CD4- or CD8-knockout (C57Bl/6) mice, 6-8 weeks old,

Table 1

Checkerboard analysis of supernatant of AdMIP-3 $\alpha$-infected A549 cells ${ }^{\mathrm{A}}$

\begin{tabular}{lcccc}
\hline Lower chamber & \multicolumn{4}{c}{ Upper chamber (\%) } \\
$(\%)$ & 0 & 25 & 50 & 100 \\
0 & $10 \pm 3$ & $14 \pm 2$ & $12 \pm 3$ & $9 \pm 2$ \\
25 & $140 \pm 9$ & $42 \pm 9$ & $33 \pm 5$ & $14 \pm 4$ \\
50 & $240 \pm 30$ & $90 \pm 6$ & $40 \pm 5$ & $19 \pm 4$ \\
100 & $691 \pm 34$ & $466 \pm 19$ & $157 \pm 10$ & $24 \pm 3$
\end{tabular}

ADifferent dilutions of supernatants of AdMIP-3a-infected A549 cells were added to upper and lower chambers. DCs were added to the upper chamber, and the culture was incubated for 90 minutes at $37^{\circ} \mathrm{C}$. Activity was expressed as the number of cells that had migrated to the lower chamber, seen in 5 high power fields (see Figure 1c for analysis of directed migration). were obtained from The Jackson Laboratories (Bar Harbor, Maine, USA). Animals were housed under specific pathogen-free conditions and treated according to National Institutes of Health guidelines.

Cell lines. CT26 is an undifferentiated colon adenocarcinoma cell line $(\mathrm{H}-2 \mathrm{~d})$ derived by intrarectal injections of $\mathrm{N}$-nitroso- $\mathrm{N}$-methylurethane in a female $\mathrm{Balb} / \mathrm{c}$ mouse (provided by N.P. Restifo, National Cancer Institute, Bethesda, Maryland, USA) (43). CT26.CL25 is derived from CT26 cells modified to express the Escherichia coli $\beta$-galactosidase ( $\beta$ gal) gene (43). The SVBalb fibroblast cell line is syngeneic to $\mathrm{Balb} / \mathrm{c}$ mice (provided by L. Gooding, Emory University, Atlanta, Georgia, USA) (44). Both the B16 murine melanoma cell line and Lewis lung cell carcinoma (LLC) cell line are syngeneic for C57Bl/ 6 mice (H-2b) (obtained from the American Type Culture Collection, Manassas, Virginia, USA). The CT26 cell line was maintained in complete RPMI-1640 media (10\% FBS, 100 $\mu \mathrm{g} / \mathrm{mL}$ streptomycin, $100 \mathrm{U} / \mathrm{mL}$ penicillin) (GIBCO BRL, Gaithersburg, Maryland, USA). The CT26.CL25 cell line was maintained in complete RPMI-1640 media containing $400 \mu \mathrm{g} / \mathrm{mL}$ G418 (GIBCO BRL). All other cell lines were maintained in complete DMEM.

Generation of DCs from bone marrow. Primary bone marrow DCs were obtained from mouse bone marrow precursors as described by Inaba et al. (45). In brief, erythrocyte-depleted murine bone marrow cells harvested from femurs were plated in complete RPMI media sup- 
a

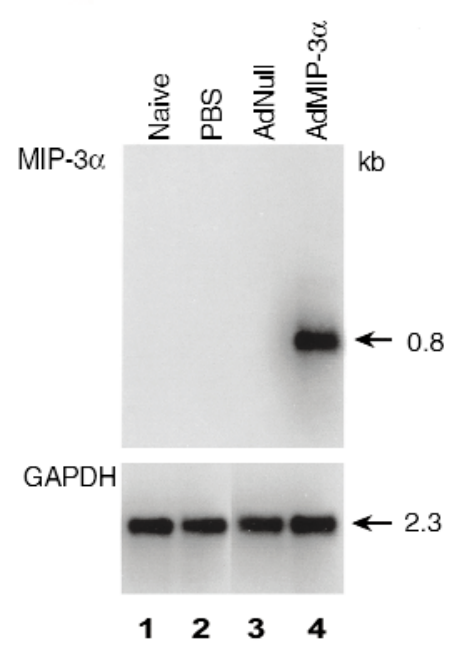

b

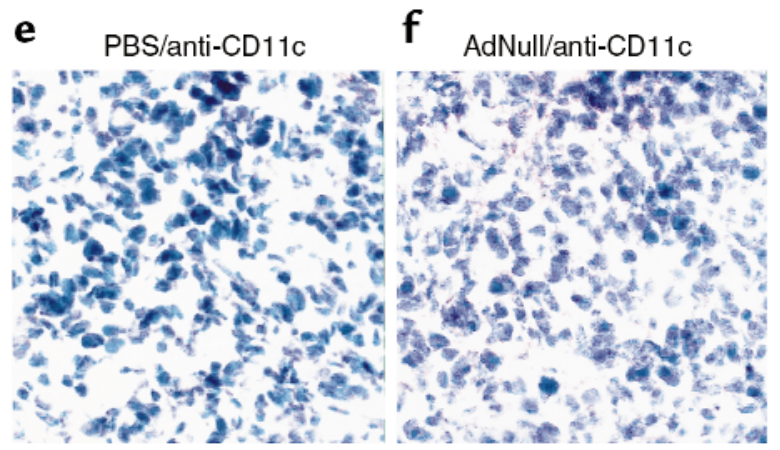

d AdMIP-3 $\alpha / a n t i-D E C 205$

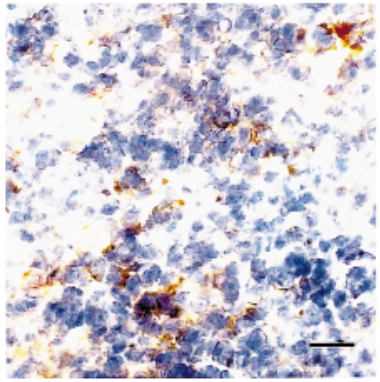

g AdMIP-3 $\alpha / a n t i-C D 11 \mathrm{c}$

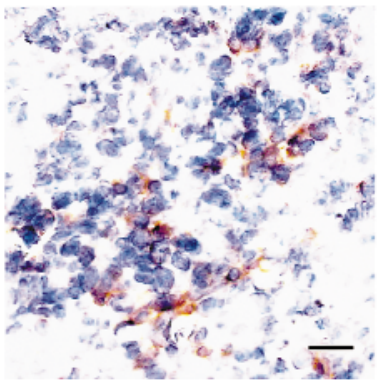

\section{Figure 2}

In vivo function of the AdMIP-3 $\alpha$ vector in tumors. (a) Northern blot analysis of B16 tumors after injection of Ad vectors. B16 tumor cells ( $3 \times$ $10^{5}$ cells) were administered subcutaneously to C57BI/ 6 mice. After 8 days, the tumors were injected with the vectors; the RNA was analyzed 3 days later. RNA extracted from the tumor $(20 \mu \mathrm{g} /$ lane $)$ was hybridized with a human MIP-3 $\alpha$ probe. Lane 1 , naive; lane 2 , PBS (100 $\mu \mathrm{L}) ;$ lane 3 , AdNull $\left(5 \times 10^{8} \mathrm{pfu} ; 100 \mu \mathrm{L}\right)$; and lane 4, AdMIP-3 $\alpha\left(5 \times 10^{8} \mathrm{pfu} ; 100 \mu \mathrm{L}\right)$. (b-e) Attraction of DCs to the area of vector administration in B16 subcutaneous tumors. B16 melanoma cells $\left(3 \times 10^{5}\right.$ cells) were administered subcutaneously to C57BI/ 6 mice. After 8 days, the tumors were injected with the vector; the tumors were evaluated 3 days later with the anti-DEC205 antibody and anti-CD11c antibody for the presence of DCs. (b) PBS $(100 \mu \mathrm{L})$ injection, anti-DEC205 antibody. (c) AdNull $\left(5 \times 10^{8}\right.$ pfu; $\left.100 \mu \mathrm{L}\right)$ injection, anti-DEC205 antibody. (d) AdMIP-3 $\alpha$ $\left(5 \times 10^{8}\right.$ pfu; $\left.100 \mu \mathrm{L}\right)$ injection, anti-DEC205 antibody. (e) PBS $(100 \mu \mathrm{L})$ injection, anti-CD11c antibody. (f) AdNull $\left(5 \times 10^{8} \mathrm{pfu} ; 100 \mu \mathrm{L}\right)$ injection, anti-CD11c antibody. (g) AdMIP- $3 \alpha\left(5 \times 10^{8}\right.$ pfu; $\left.100 \mu \mathrm{L}\right)$ injection, anti-CD11c antibody. Note in panels $\mathbf{d}$ and $\mathbf{g}$, there is an accumulation of DEC205-positive and CD11c-positive cells in the tumors after administration of the AdMIP-3 $\alpha$ vector. Bar, $10 \mu \mathrm{m}$.

plemented with recombinant murine GM-CSF (100 $\mathrm{U} / \mathrm{mL})$ and recombinant murine IL-4 (20 ng/mL; Genzyme, Farmington, Massachusetts, USA). On days 2 and 4 , nonadherent granulocytes were gently removed and fresh media were added. On day 6 , loosely adherent proliferating DC aggregates were dislodged and replated. On day 6 of culture, nonadherent cells with the typical morphological features of DCs were used for the in vitro migration assay to test the function of the AdMIP- $3 \alpha$ vector (see later here).

Function of AdMIP-3 $\alpha$ in vitro. To evaluate the MIP- $3 \alpha$ mRNA expressed from AdMIP-3 $\alpha$ vector, the A549 lung carcinoma cell line was infected with AdMIP-3 $\alpha$ or the AdNull control vector (each, 10 moi). After 3 days, total RNA was extracted using Trizol reagents (GIBCO BRL). RNA samples were separated by electrophoresis on a $1 \%$ agarose gel containing $0.66 \mathrm{M}$ formaldehyde, blotted onto a filter membrane (Duralon-UV; Stratagene, La Jolla, California, USA). Hybridization was carried out with ${ }^{32}$ P-labeled probes (Prime It kit; Stratagene) at $65^{\circ} \mathrm{C}$ in Quick-Hyb solution (Stratagene). Membranes were washed twice for 5 minutes at room temperature in $2 \times$ SSC and $0.1 \%$ SDS and once at $65^{\circ} \mathrm{C}$ in $0.1 \times$ SSC and $0.1 \%$ SDS and were exposed with $\mathrm{x}$-ray film at $-80^{\circ} \mathrm{C}$ with an intensifying screen.
To demonstrate that production of the MIP- $3 \alpha$ protein was directed by the AdMIP- $3 \alpha$ vector, cells and culture supernatants of A549 cells infected with AdMIP$3 \alpha$ or AdNull (each, 10 moi) for 3 days were prepared and used for Western analysis. The A549 cells were lysed in extraction buffer (4\% SDS, $250 \mathrm{mM}$ Tris-HCl [pH 6.8], $10 \%$ glycerol, $1 \% \beta$-mercaptoethanol) for 10 minutes at $95^{\circ} \mathrm{C}$. The cell lysates were centrifuged at $12,000 \mathrm{~g}$ for 10 minutes at $4^{\circ} \mathrm{C}$, and $5 \mu \mathrm{L}$ of the lysate supernatants was separated in an $18 \%$ Tris- $\mathrm{HCl}$ gel (Bio-Rad Laboratories, Hercules, California, USA) by SDS-polyacrylamide gel electrophoresis and electrotransferred onto supported nitrocellulose membrane $(0.45 \mu \mathrm{m})$ (Bio-Rad Laboratories). Immunological detection using anti-human MIP-3 $\alpha$ polyclonal antibody (R\&D Systems Inc., Minneapolis, Minnesota, USA) was performed by the enhanced chemiluminescence method according to the instructions of the manufacturer (Amersham Life Sciences Inc., Arlington Heights, Illinois, USA).

To evaluate the function of the MIP- $3 \alpha$ protein directed by the AdMIP- $3 \alpha$ vector, directed migration of DCs induced by supernatants of A549 cells infected with AdMIP- $3 \alpha$ was assayed by a modification of Boyden's chamber method using microchemotaxis chambers and 
filters (5- $\mu \mathrm{m}$ diameter) (46). Murine DCs were suspended at a concentration of $10^{6}$ cells $/ \mathrm{mL}$ in RPMI medium 1640 supplemented with $1 \%$ FBS. Fifty microliters of suspension was placed in the upper chamber, and $25 \mu \mathrm{L}$ of supernatant of A549 cells infected for 3 days with AdMIP-3 $\alpha$, or AdNull, or naive, uninfected cells was placed in the lower chamber. The chamber was incubated for 90 minutes at $37^{\circ} \mathrm{C}$. Directed migration was expressed as the number of cells that had migrated to the lower chamber, seen in 5 high power fields. Checkerboard analysis of the supernatants of AdMIP- $3 \alpha$-infected A549 cells was carried out to distinguish chemotaxis from chemokinesis. Different dilutions of supernatants were added to upper and lower chambers, and the apparatus was incubated for 90 minutes at $37^{\circ} \mathrm{C}$. Directed migration was expressed as the number of cells that had migrated to the lower chamber, seen in 5 high power fields. The data are presented as mean \pm SE.

In vivo function of the AdMIP-3 $\alpha$ vector in tumors. To demonstrate functional expression of MIP- $3 \alpha$ after AdMIP- $3 \alpha$ administration to tumors, B16 tumor cells $\left(3 \times 10^{5}\right.$ cells $)$ were administered subcutaneously to C57Bl/ 6 mice. After 8 days, the tumors were injected with AdMIP-3 $\alpha\left(5 \times 10^{8}\right.$ pfu in $\left.100 \mu \mathrm{L}\right)$, AdNull $\left(5 \times 10^{8}\right.$ pfu in $100 \mu \mathrm{L})$, or PBS $(100 \mu \mathrm{L})$. To demonstrate expression of the AdMIP- $3 \alpha$ in the tumors, Northern analysis was carried out as already described here. RNA was extracted from tumors 3 days after intratumoral administration and hybridized $(20 \mu \mathrm{g} /$ lane $)$ with a human MIP-3 $\alpha$ probe or a GAPDH probe.

The ability of the AdMIP- $3 \alpha$ vector to produce a protein that functioned in vivo to attract DCs was evaluated in tumors 3 days after administration of the AdMIP$3 \alpha$, AdNull, PBS, or controls. Three days after intratumoral injection $\left(5 \times 10^{8} \mathrm{pfu}\right.$ in $\left.100 \mu \mathrm{L}\right)$, mice were sacrificed and the tumor was harvested. Cryostat sections $(8 \mu \mathrm{m})$ were placed on the slides, air dried, fixed in acetone for 10 minutes, and air dried for at least 30 minutes. After washing in PBS/0.01\% Triton X100, the slides were incubated with PBS/0.01\% Triton X 100/5\% normal goat serum for 60 minutes, then incubated overnight at $4^{\circ} \mathrm{C}$ with a $1: 25$ dilution of rat anti-mouse DC antibody (anti-DEC205, NLDC145; Serotec, Washington, DC, USA), 1:50 dilution of hamster anti-mouse $\mathrm{CD} 11 \mathrm{c}$ mAb (PharMingen, San Diego, California, USA), rat control IgG2a (Serotec), or hamster IgG, group 1. $\lambda$ (Pharmingen). To identify T cells, anti-mouse CD8b.2 mAb (Ly-3.2; PharMingen), anti-mouse CD4 (L3T4; PharMingen), control rat IgG1, $\kappa$ isotype standard (PharMingen), and rat IgG2a were used. After washing in PBS $/ 0.01 \%$ Triton X 100 , the slides were incubated with a 1:100 dilution of horseradish peroxidase-conjugated monoclonal anti-rat $\kappa$ and $\lambda$ light chains (Sigma Chemical Co., St. Louis, Missouri, USA) or horseradish peroxidase-conjugated anti-hamster IgG (Serotec), and the slides were examined using microscope.
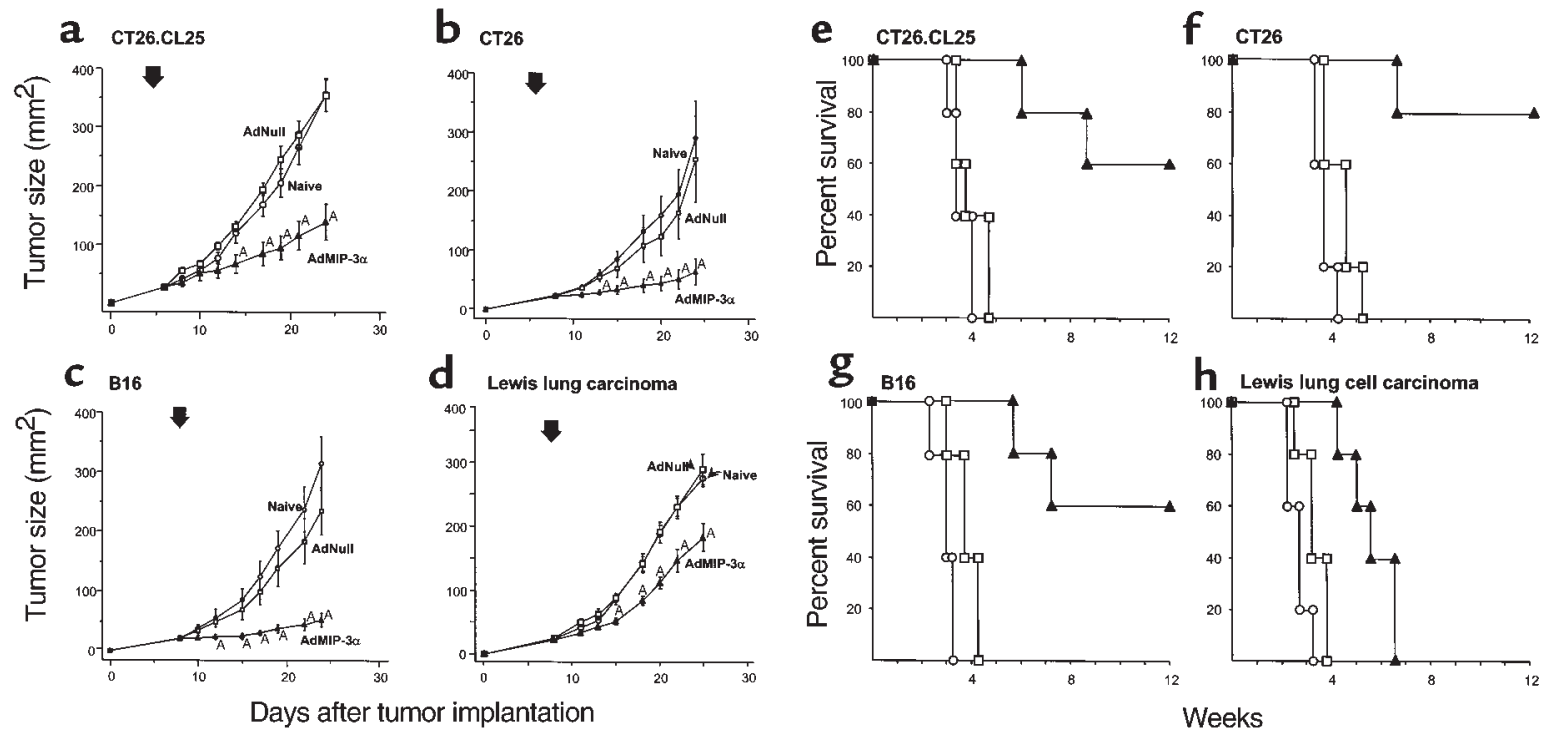

Figure 3

Effects of AdMIP-3 $\alpha$ administration on progression of preexisting subcutaneous tumors. (a-d) Tumor growth. (a) Effects of AdMIP-3 $\alpha$ on CT26.CL25 tumor progression. Balb/c mice were injected subcutaneously on day 0 with $3 \times 10^{5}$ CT26.CL25 tumor cells. Six days later, $5 \times$ $10^{8} \mathrm{pfu}$ (in $100 \mu \mathrm{L}$ ) AdMIP-3 $\alpha$ (filled triangle) or AdNull (open square) were injected intratumorally; naive animals were used as a further control (open circle). Tumor size was monitored three times each week. (b) Effects of AdMIP-3 $\alpha$ administration on the progression of CT26 tumors in Balb/c mice. The experiments (and symbols) were similar to those in a except mice were injected on day 0 with $3 \times 10^{5} \mathrm{CT} 26 \mathrm{colon}$ carcinoma cells, and 8 days later, $5 \times 10^{8}$ pfu AdMIP- $3 \alpha$ or AdNull $(100 \mu \mathrm{L})$ was administered. (c) Same as b (including symbols), but with B16 melanoma cells in C57Bl/ 6 mice $\left(3 \times 10^{5}\right.$ cells injected subcutaneously at day 0 , vectors administered at day 8$)$. (d) Same as b, but with LLC cells in C57BI/ 6 mice $\left(3 \times 10^{5}\right.$ cells injected subcutaneously at day 0 , vectors administered at day 8$)$. In a-d, the arrow indicates the time of vector administration. ATumor growth significantly inhibited $(P<0.05)$ in the AdMIP-3 $\alpha$-treated group compared with all controls (AdNull or naive). (e-h) Survival. The survival data are derived from the same animals as in a-d. (e) CT26.CL25 tumors, Balb/c mice. (f) CT26 tumors, Balb/c mice. (g) B16 tumors, C57Bl/6 mice. (h) LLC carcinoma, C57BI/6 mice. 
To demonstrate AdMIP- $3 \alpha$ modification of tumor growth in vivo, mice were injected subcutaneously on day 0 with tumor cells $\left(3 \times 10^{5}\right)$ including CT26.CL25 $(n$ $=30$ mice $)$, CT26 $(n=30), \mathrm{B} 16(n=30)$, and LLC $(n=30)$. All injections were performed into the shaved right (or bilateral) flank(s) in a total volume of $100 \mu \mathrm{L}$. When the tumors had grown to $15-25 \mathrm{~mm}^{2}$ (day 6 for CT26.CL25; day 8 for CT26, B16, and LLC), mice were inoculated into the tumors with $100 \mu \mathrm{L}$ of the AdMIP- $3 \alpha$ or AdNull vectors $\left(5 \times 10^{8} \mathrm{pfu}\right)$ in PBS. The size of each tumor was monitored three times weekly. The tumor area was calculated and expressed as the average tumor area $\left(\mathrm{mm}^{2}\right) \pm \mathrm{SE}$. If animals appeared moribund or the diameter of the tumors reached $20 \mathrm{~mm}$, the mice were sacrificed, and this was recorded as the date of death for survival studies. Survival of the animals was assessed using standard methodology. To evaluate the inflammation of lymph nodes after intratumoral injection of AdMIP- $3 \alpha$, ipsilateral, and contralateral inguinal lymph nodes were isolated 3 days after Ad vector injection into tumors (see later discussion here), and wet weight was measured. DCs attracted in inguinal lymph nodes 3 days after intratumoral administration of the AdMIP$3 \alpha$, AdNull, or PBS were assessed by immunohistochemistry as already described here.

Tumor-specific cytotoxic Tlymphocytes. To assess the ability of intratumoral injection of AdMIP- $3 \alpha$ to induce tumorspecific cytotoxic T lymphocytes (CTLs), splenocytes were isolated 12 days after Ad vector injection into the tumors (see earlier here) and restimulated at $3 \times 10^{6}$ cells $/ \mathrm{mL}$ with $10^{6}$ cells $/ \mathrm{mL}$ irradiated (50 Gy) tumor cells. After 5 days of culture, the in vitro restimulated splenocytes were quantified using a ${ }^{51} \mathrm{Cr}$-release assay for their ability to lyse tumor cells. The percentage of specific a ${ }^{51} \mathrm{Cr}$ release was expressed as follows: $100 \times$ (experimental release - spontaneous release) / (maximal release - spontaneous release). SVBalb and C3 cells were used as control for Balb/c- and C57Bl/6-syngeneic tumors, respectively.

Adoptive transfer of splenocytes. To demonstrate that in vivo administration of the AdMIP- $3 \alpha$ vector sensitized the cellular host defense system against the relevant tumor, 10 days after the inoculation of the four types of tumors with Ad vectors (see earlier discussion here), the spleens were removed. Splenocytes $\left(3 \times 10^{7}\right.$ cells per mouse) were injected into recipient animals by tail vein. Seven days later (day 0), recipient animals were challenged by subcutaneous injection in the right flank with $3 \times 10^{5}$ relevant tumor cells. Survival was assessed as already described here.

Statistical analysis. The data are presented as mean \pm SE. Statistical analysis was performed using two-way ANOVA. Statistical significance was determined at $P<$ 0.05 . Survival estimates and median survivals were determined using the method of Kaplan and Meier.

\section{Results}

Function of AdMIP-3 $\alpha$ in vitro. The function of AdMIP- $3 \alpha$ vector to produce a functional MIP- $3 \alpha$ protein was confirmed in vitro by Northern analysis, Western blot
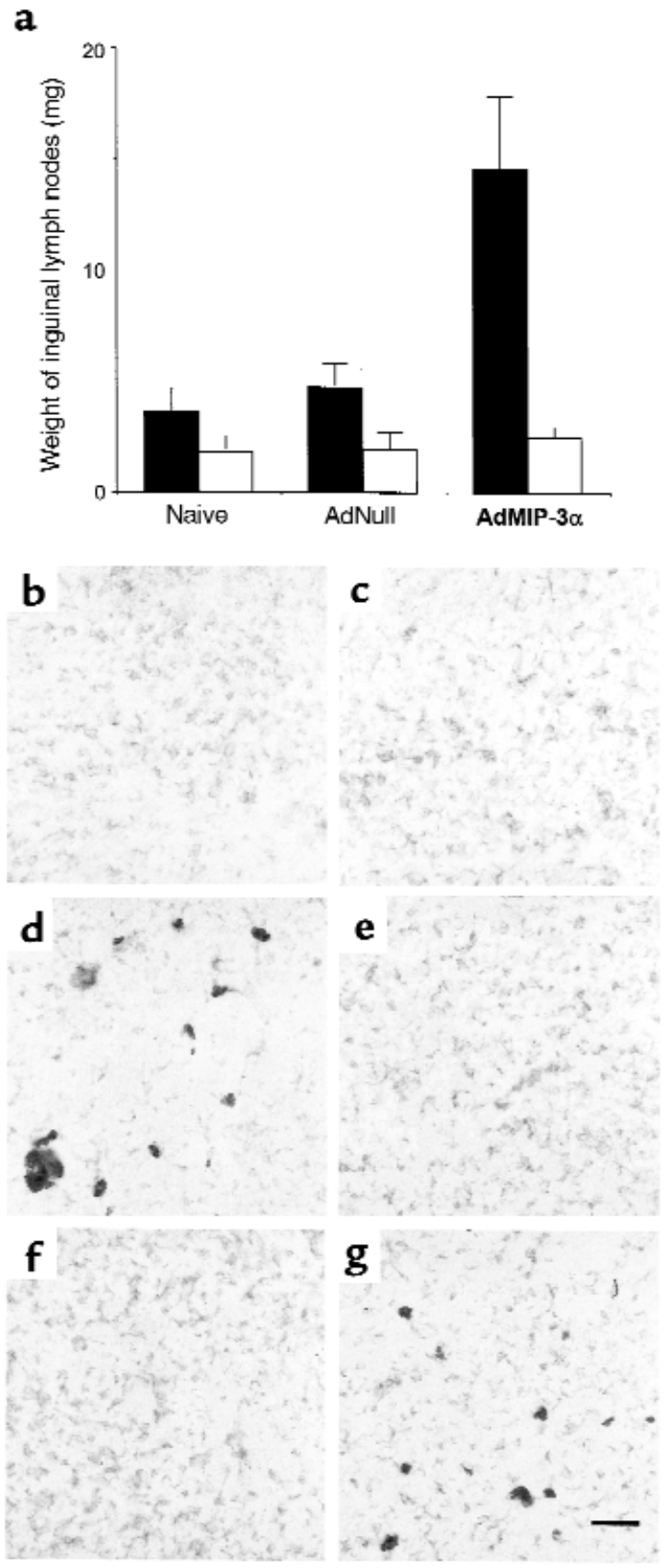

Figure 4

Inflammation of inguinal lymph nodes after inoculation of AdMIP$3 \alpha$. (a) The weight of inguinal lymph nodes. CT26 colon carcinoma cells $\left(3 \times 10^{5}\right.$ cells $)$ were administered subcutaneously to the right flank of Balb/c mice. After 8 days, the tumors were injected with the vectors. Three days later, bilateral inguinal lymph nodes were harvested and weighed (wet). AdMIP-3 $\alpha$ induced a significant increase in the weight of lymph nodes of the tumor-bearing side, compared with controls. Right side, tumor-bearing side (filled square); left side, non-tumor-bearing side (open square). (b-e) Accumulation of DCs in ipsilateral inguinal lymph nodes. Lymph nodes were evaluated with the anti-DEC205 antibody and anti-CD11c antibody for the presence of DCs. (b) PBS $(100 \mu \mathrm{L})$ injection, anti-DEC205 antibody. (c) AdNull $\left(5 \times 10^{8}\right.$ pfu; $\left.100 \mu \mathrm{L}\right)$ injection, anti-DEC205 antibody. (d) AdMIP-3 $\alpha\left(5 \times 10^{8}\right.$ pfu; $\left.100 \mu \mathrm{L}\right)$ injection, anti-DEC205 antibody. (e) PBS $(100 \mu \mathrm{L})$ injection, anti-CD11c antibody. (f) AdNull $\left(5 \times 10^{8}\right.$ pfu; $100 \mu \mathrm{L})$ injection, anti-CD11c antibody. (g) AdMIP-3 $\alpha\left(5 \times 10^{8}\right.$ pfu; $100 \mu \mathrm{L}$ ) injection, anti-CD11c antibody. Bar, $50 \mu \mathrm{m}$. 

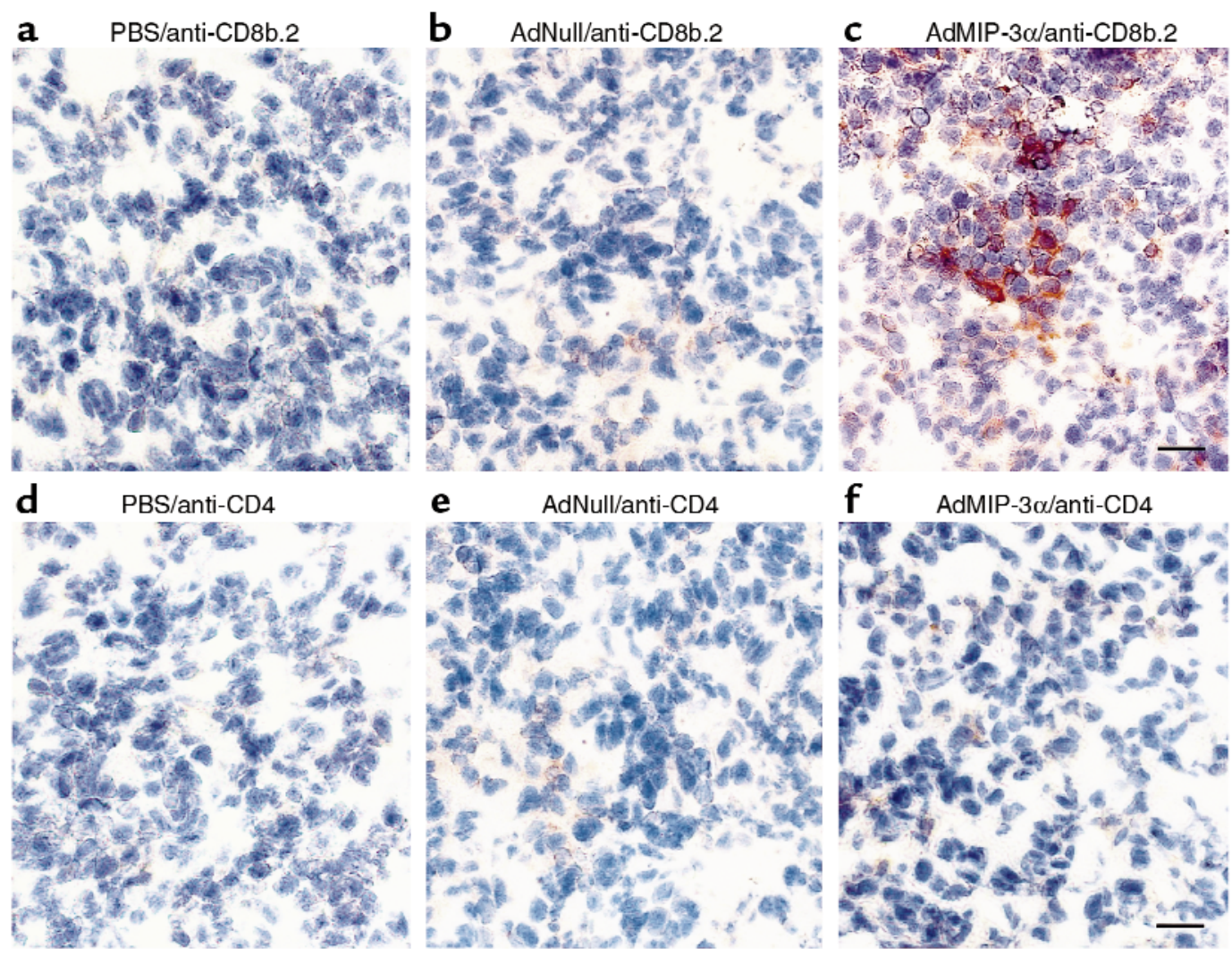

\section{Figure 5}

T-cell infiltration in CT26 subcutaneous tumors after intratumoral administration of AdMIP- $3 \alpha$. CT2 26 colon carcinoma cells $\left(3 \times 10^{5}\right.$ cells) were administered subcutaneously to Balb/c mice. After 8 days, the tumors were injected with the vectors; the tumors were evaluated 10 days later with anti-CD8b. 2 and anti-CD4 antibodies. (a) PBS (100 $\mu \mathrm{L})$ injection, anti-CD8b. 2 antibody. (b) AdNull $\left(5 \times 10^{8}\right.$ pfu; $\left.100 \mu \mathrm{L}\right)$ injection, anti-CD8b. 2 antibody. (c) AdMIP-3 $\alpha\left(5 \times 10^{8}\right.$ pfu; $\left.100 \mu \mathrm{L}\right)$ injection, anti-CD8b. 2 antibody. (d) PBS (100 $\left.\mu \mathrm{L}\right)$ injection, anti-CD4 antibody. (e) AdNull ( $\left.5 \times 10^{8} \mathrm{pfu} ; 100 \mu \mathrm{L}\right)$ injection, anti-CD4 antibody. (f) AdMIP-3 $\alpha\left(5 \times 10^{8} \mathrm{pfu} ; 100 \mu \mathrm{L}\right)$ injection, anti-CD4 antibody. Note in $\mathbf{c}$, there is an accumulation of CD8b.2+ cells in response to Ad MIP-3 $\alpha$, and in $\mathbf{f}$, an accumulation (to a lesser extent) of CD4+ cells. Bar, $10 \mu \mathrm{m}$. Other tumors gave similar results.

analysis, and chemotaxis assay. After infection of A549 cells with AdMIP- $3 \alpha$ for 3 days, MIP- $3 \alpha$ mRNA was strongly induced but not in controls (Figure 1a). Western analysis using an anti-human MIP-3 $\alpha$ polyclonal antibody demonstrated that MIP- $3 \alpha$ protein was barely detected in the cell lysate, but easily identified in the culture supernatant (consistent with that of a secreted protein) of A549 cells infected with AdMIP-3 $\alpha$ (Figure 1b). Control cultures demonstrated no MIP- $3 \alpha$ in the cell lysate or supernatant. To confirm the biologic activity of the secreted human MIP-3 $\alpha$, chemotaxis for DC was assessed (Figure 1c). The supernatant of A549 cells infected with AdMIP- $3 \alpha$ showed markedly increased chemotactic activity for DCs compared with controls. Checkerboard analysis demonstrated that the migration of DCs induced by the AdMIP- $3 \alpha$ supernatant was due to the stimulation of directed migration (chemotaxis) toward the attractant rather than simply an increase in random motility (chemokinesis; Table 1).

Function of AdMIP-3 $\alpha$ in vivo. The ability of the AdMIP$3 \alpha$ vector to function in tumors was confirmed in vivo by Northern blot analysis and immunohistochemistry. B16 tumor cells $\left(3 \times 10^{5}\right.$ cells) were injected subcuta- neously to C57Bl/6 mice. After 8 days, the tumors were injected with PBS, AdNull, or AdMIP-3 $\alpha$. RNA was extracted 3 days after vector administration from the tumor and hybridized with a human MIP- $3 \alpha$ probe. The MIP-3 $\alpha$ mRNA was detected only in the B16 tumor injected with AdMIP-3 $\alpha$ (Figure $2 \mathrm{a}$ ). To ascertain the accumulation of DCs in tumors, B16 tumors 3 days after administration of the AdMIP-3 $\alpha$ or controls were examined with the anti-DEC205 antibody and anti-CD11c antibody for the presence of DCs by immunohistochemistry. DCs were stained with both anti-DEC 205 and anti-CD11c, which showed the accumulation of DCs in B16 subcutaneous tumors induced by the AdMIP-3 $\alpha$ vector, but not in controls (Figure $2, \mathrm{~b}-\mathrm{g}$ ).

AdMIP-3 $\alpha$ modification of tumor growth in vivo. Intratumoral injection of AdMIP- $3 \alpha$ inhibited the growth of four different murine tumors (Figure 3). In the CT26.CL25 tumor model in Balb/c mice (H-2d), treatment with AdMIP-3 $\alpha$ induced significant inhibition of tumor growth $(P<0.05)$ and there was significant long-term survival, whereas administration of AdNull had no beneficial effect (Figure 3, a and e). In the CT26 tumor model in Balb/c mice, tumor size of 
AdMIP- $3 \alpha$-treated mice also regressed significantly compared with that of control groups $(P<0.05)$, and there was significant long-term survival $(P<0.05$; Figure $3, \mathrm{~b}$ and $\mathrm{f}$ ). In the $\mathrm{B} 16$ tumor model in $\mathrm{C} 57 \mathrm{Bl} / 6$ mice $(\mathrm{H}-2 \mathrm{~b})$, tumor growth was also suppressed significantly by AdMIP-3 $\alpha(P<0.05)$ and there was significant long-term survival $(P<0.05$; Figure $3, \mathrm{c}$ and $\mathrm{g})$. In the less immunogenic LLC model in C57Bl/6 mice, tumor size was also inhibited significantly by AdMIP-3 $\alpha(\mathrm{P}<0.05)$, although to a lesser degree than the other models, but there is no enhanced survival $(P$ $>0.1$; Figure 3 , d and h).

Intratumoral injections of AdMIP- $3 \alpha$ induced the inflammation of regional lymph nodes of tumorbearing side (Figure 4a). The weight of inguinal lymph nodes was significantly increased in AdMIP$3 \alpha$-treated group compared with naive and AdNulltreated group $(P<0.05)$. Microscopic examination showed the inflammatory enlargement of lymph nodes without metastasis (data not shown). Ipsilateral inguinal lymph nodes were examined with antiDEC205 antibody and anti-CD11c antibody for the presence of DCs by immunohistochemistry. DCs stained with both anti-DEC205 and anti-CD11c were accumulated in ipsilateral inguinal lymph nodes after intratumoral injection of AdMIP- $3 \alpha$ vector, but not in controls (Figure 4, b-g).

Induction of cellular immunity. Intratumoral administration of AdMIP- $3 \alpha$ was associated with the accumulation of mostly CD8b.2-positive $\mathrm{T}$ cells infiltrating
CT26 subcutaneous tumors. For example, when CT26 colon carcinoma tumor growing in Balb/c mice was injected with AdMIP-3 $\alpha$, CD8b.2-positive cells were significantly increased, with lesser numbers of CD4positive cells evident (Figure 5). Similar results were observed with the CT26.CL25, B16, and LLC tumors (data not shown).

Transduction with AdMIP- $3 \alpha$ elicited tumor-specific CTL activity in all four tumor models. Balb/c mice bearing CT26.CL25 tumors were intratumorally inoculated with AdMIP-3 $\alpha$ or AdNull. Effector cells generated from splenocytes 12 days after the inoculation by culture with irradiated CT26.CL25 tumor cells exhibited specific lysis of CT26.CL25 target cells in cells obtained only from AdMIP-3 $\alpha$-treated animals (Figure 6a). No apparent lysis was observed against syngeneic fibroblast SVBalb cells. In animals with CT26, B16 and LLC carcinoma tumors, effector cells from only AdMIP-3 $\alpha$-treated mice also exhibited specific lysis of relevant target cells (Figure 6, b-d). Evidence that in vitro specific cytolysis was relevant in vivo came from studies demonstrating that adoptive transfer of splenocytes protected against a subsequent challenge with the identical tumor cells in all four tumor models $(P<0.05$; Figure 7$)$.

Tumor inhibition by AdMIP- $3 \alpha$ administration was dependent on CD8 T cells (Figure 8). C57Bl/6 wildtype or CD4- or CD8-knockout mice bearing B16 melanoma were intratumorally inoculated with AdMIP- $3 \alpha$. Treatment with AdMIP-3 $\alpha$ induced significant inhibition of tumor growth in wild-type mice

\section{Figure 6}

Cytotoxic $T$ cells directed against specific tumors after intratumoral administration of AdMIP-3 $\alpha$.

(a) CTL against CT26.CL25 tumor cells. Balb/c mice were injected subcutaneously with $3 \times 10^{5}$ CT26.CL25 cells. Six days later, Ad vectors $(5 \times$ $10^{8} \mathrm{pfu} ; 100 \mu \mathrm{L}$ ) were injected into the tumors. Spleens were removed 12 days after Ad vector injection, and splenic mononuclear cells were cocultured with irradiated (50 Gy) CT26.CL25 cells. After 5 days of culture, the in vitro CTL activity of the restimulated splenocytes was assessed against CT26.CL25 or SVBalb as control using a ${ }^{51} \mathrm{Cr}$-release assay. (b) CTL against CT26 tumor cells. Balb/c mice were injected subcutaneously with $3 \times 10^{5} \mathrm{CT} 26$ cells. Eight days later, Ad vectors $\left(5 \times 10^{8} \mathrm{pfu} ; 100 \mu \mathrm{L}\right)$ were injected. The assessment of CTL was carried out 12 days later as in a, but using CT26 or SVBalb (control) cells. (c) CTL against $\mathrm{B} 16$ cells. $\mathrm{C} 57 \mathrm{Bl} / 6$ mice were injected subcutaneously with $3 \times 10^{5}$ B16 cells. Eight days later, Ad vectors $\left(5 \times 10^{8} \mathrm{pfu} ; 100 \mu \mathrm{L}\right)$ were injected. The assessment of $C T L$ was carried out 12 days later as in a, but using B16 or C3 (control) cells. (d) CTL against LLC cells. C57BI/6 mice were injected subcutaneously with $3 \times 10^{5}$ LLC cells. Eight days later, Ad vectors $\left(5 \times 10^{8}\right.$ pfu; $100 \mu \mathrm{L}$ ) were injected. The assessment of $C T L$ was carried out 12 days later as in a, but using LLC or C3 (control) cells.
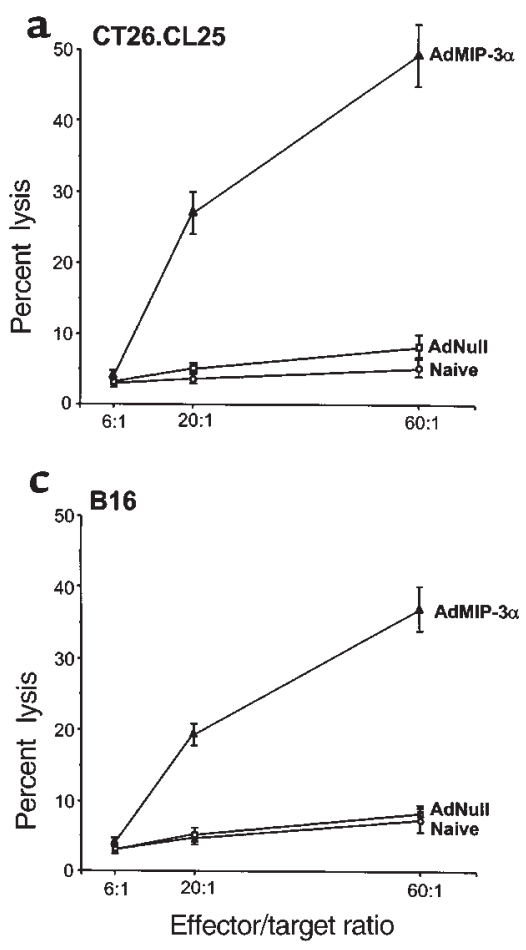

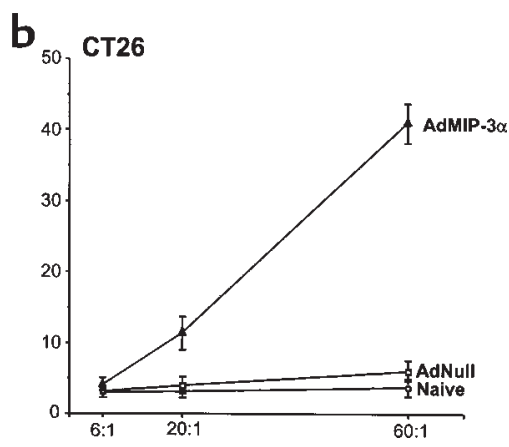

d

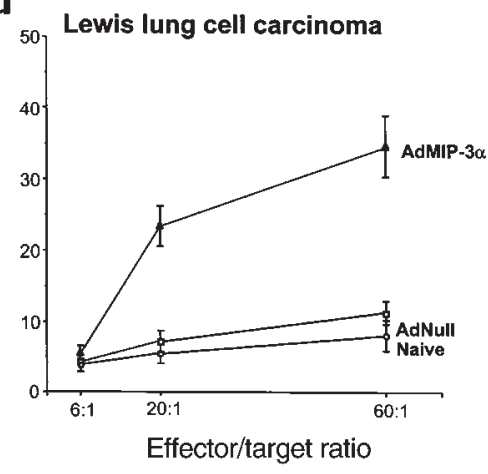




\section{Figure 7}

Ability of adoptive transfer of splenocytes from syngeneic mice treated with AdMIP-3 $\alpha$ to protect recipient mice from growth of subcutaneous tumors. Mice were injected subcutaneously with $3 \times 10^{5}$ tumor cells. Six or 8 days later, AdMIP-3 $\alpha\left(5 \times 10^{8}\right.$ pfu; $\left.100 \mu \mathrm{L}\right)$ and AdNull $\left(5 \times 10^{8} \mathrm{pfu} ; 100 \mu \mathrm{L}\right)$ were injected into the tumors. Ten days later, the spleens were removed. Splenocytes $\left(3 \times 10^{7}\right.$ cells per mouse) from AdMIP$3 \alpha$-treated (filled triangle), AdNull-treated (open square), or untreated (open circle) mice were injected into recipient animals by tail vein. Seven days later (day 0 ), recipient animals were challenged by subcutaneous injection in the right flank with $3 \times 10^{5}$ tumor cells. Controls included tumor challenge only without adoptive transfer of splenocytes (filled circle). (a) CT26.CL25 tumors. (b) CT26 tumors. (c) B16 tumors. (d) LLC tumors. a

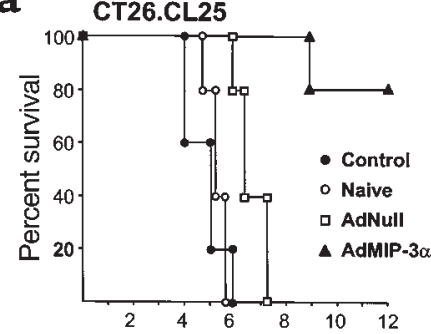

c

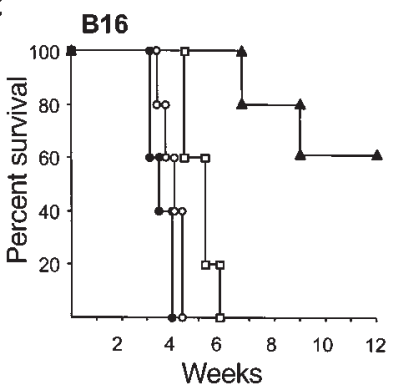

b

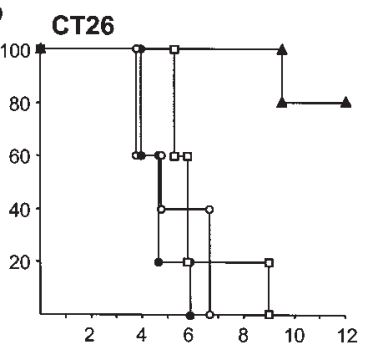

d

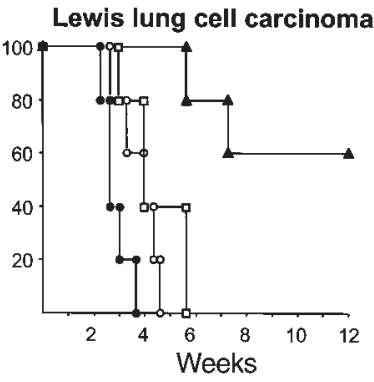

and CD4-knockout mice $(P<0.05)$. There was no effect in CD8-knockout mice (Figure 8a). In an LLC model, tumor size of AdMIP-3 $\alpha$-treated wild-type and CD4-knockout mice also regressed significantly compared with that of control and CD8-knockout mice $(P<0.05)$, although to a lesser degree.

Intratumoral injection of AdMIP-3 $\alpha$ inhibited the progression of distant subcutaneous tumor (Figure 9). Balb/c mice bearing CT26 colon carcinoma in bilateral flanks were intratumorally inoculated with AdMIP- $3 \alpha$ into the tumor in the right flank. Tumor growth on the left flank (noninjection side) was significantly inhibited compared with that in the naive and AdNull controls $(P<0.05)$.

\section{Discussion}

This study is based on the hypothesis that in vivo transfer of the coding sequences of the MIP- $3 \alpha$ gene to established tumors using a recombinant adenovirus will result in expression of MIP-3 $\alpha$ in the tumor and in attraction of DCs to the injection site of tumor, and will initiate a tumor-specific cellular immune response that will suppress growth of tumors and increase survival of the host. The results support this hypothesis. In vivo administration of the AdMIP-3 $\alpha$ vector to four different types of murine tumors elicited therapeutic antitumor immunity that suppressed the growth of all preexisting tumors and resulted in enhanced survival in three of four tumor models. Administration of a

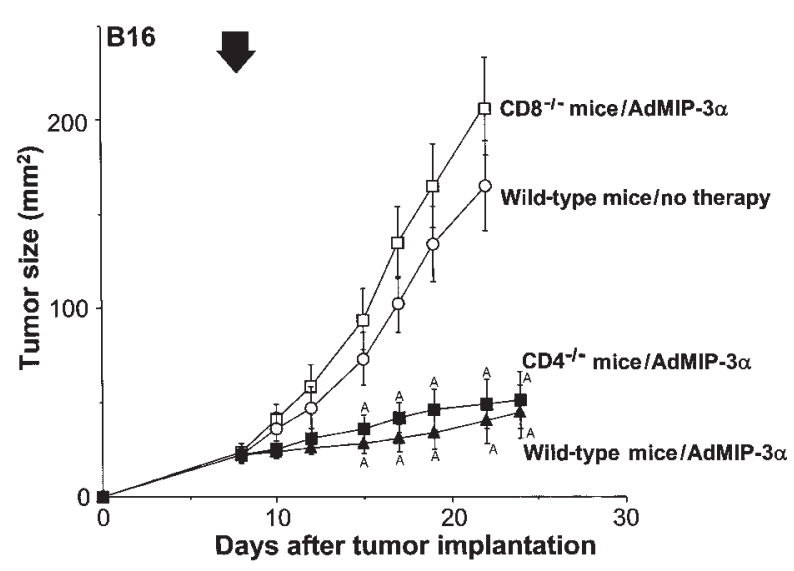

b

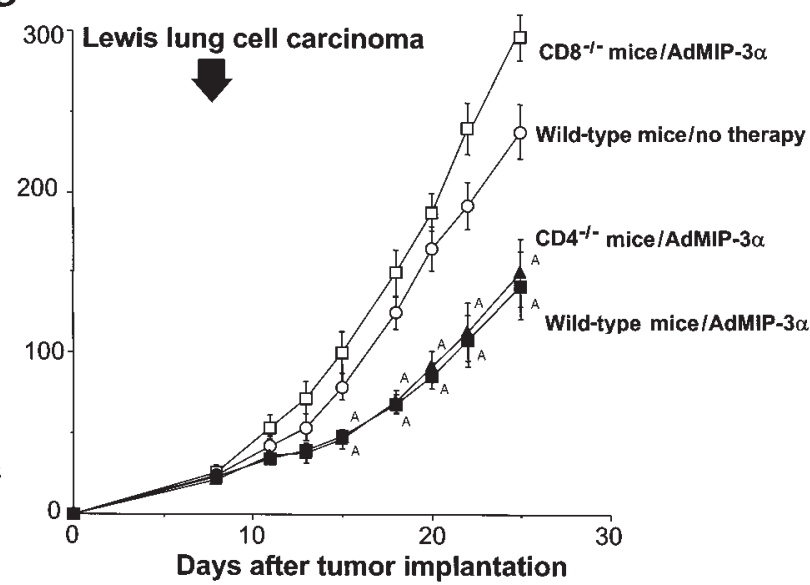

\section{Figure 8}

T-cell dependency on effects of AdMIP-3 $\alpha$ administration on progression of preexisting subcutaneous tumors. (a and $\mathbf{b})$ Tumor growth. (a) Effects of AdMIP-3 $\alpha$ on B16 melanoma. C57BI/ 6 mice were injected subcutaneously on day 0 with $3 \times 10^{5}$ B16 melanoma cells. Eight days later, $5 \times 10^{8} \mathrm{pfu}$ (in $100 \mu \mathrm{L}$ ) AdMIP-3 $\alpha$ were injected intratumorally in CD8-knockout mice (open squares) or CD4-knockout mice (filled squares). Tumor size was monitored three times a week. (b) Effects of AdMIP-3 $\alpha$ on LLC. The experiments (and symbols) are similar to those in a, except the mice were injected on day 0 with $3 \times 10^{5} \mathrm{LLC}$ cells. The arrow indicates the time of vector administration. ${ }^{\text {ATumor }}$ growth was significantly inhibited $(P<0.05)$ in the AdMIP-3 $\alpha$-treated groups compared with the control (no therapy) and CD8-knockout mice. 
AdMIP-3 $\alpha$ attracted DCs to the tumors, increased the number of CD8b.2+ T cells in the tumor, and elicited tumor-specific cytotoxic $\mathrm{T}$ lymphocytes sufficient to protect naive mice against a subsequent tumor challenge after transfer of splenocytes from AdMIP$3 \alpha$-treated mice. In CD8-knockout mice, no therapeutic effect of AdMIP- $3 \alpha$ administration was observed, suggesting a CD8-dependent mechanism in the antitumor effect. Intratumoral injection of AdMIP-3 $\alpha$ also inhibited the growth of distant tumors.

DC trafficking. DCs are powerful antigen-presenting cells that function as the principal activators of $\mathrm{T}$ cells and initiate immune responses (1). DCs are found at many sites in the body, but mostly at sites of frequent exposure to antigens, and where the DC can interact with other components of the immune system $(1,2)$. After exposure to antigens, DCs migrate from nonlymphoid tissue to T-cell areas of lymphoid tissues (1, $2,47,48)$. During their migration from peripheral tissues to lymphoid tissues, DC undergo a maturation process encompassing dramatic changes in phenotype and function $(1,2,49,50)$. Most importantly, immature DCs capture and process soluble proteins efficiently, whereas mature DCs are in poor in antigen capture and processing but markedly efficient in priming naive $T$ cells $(1,2)$.

The mediators that attract DCs to sites where they interact with antigens are not well understood. A variety of molecules have been reported to influence DC migration, including LPS, GM-CSF, IL- $1 \beta$, and TNF- $\alpha$ (51-57). The relative importance of these mediators in vivo is not defined; for example, anti-TNF- $\alpha$ antibodies do not prevent DC migration induced by LPS in vivo (55). There is emerging evidence that some chemokines may play important roles in the migration of DCs to secondary lymphoid tissues. In addition to C5a, platelet-activating factor (PAF) and formyl peptides (FMLPs), several chemokines induce directional migration of Langerhans cells, monocyte-derived DCs, and/or CD34+ cell-derived DC in vitro, including the CC chemokines RANTES (regulated on activation, normal $\mathrm{T}$ cell expressed and secreted), macrophage inflammatory protein-1 $\alpha$ (MIP- $1 \alpha)$, MIP-1 $\beta$, MIP-3 $\alpha$, monocyte

\section{Figure 9}

Effects of AdMIP- $3 \alpha$ on progression of distant preexisting subcutaneous tumors. Balb/c mice were injected subcutaneously on day 0 with $3 \times 10^{5} \mathrm{CT} 26$ colon carcinoma cells into bilateral flanks. Eight days later, $5 \times 10^{8} \mathrm{pfu}$ (in $100 \mu \mathrm{L}$ ) AdMIP- $3 \alpha$ (filled triangle) or AdNull (open square) were injected in the right-side tumor; naive animals were used as a further control (open circle). Tumor size of leftside (noninjection side) was monitored three times per week; the arrow indicates the time of vector administration. ATumor growth was significantly inhibited $(P<0.05)$ in the AdMIP-3 $\alpha$-treated group compared with all controls (AdNull or naive). chemotactic protein-1 (MCP-1), MCP-2, MCP-3, MCP4, MIP-5/human CC cytokine-2 (HCC2), macrophagederived chemokine (MDC), and the CXC chemokine stromal cell-derived factor (SDF-1) $(37,58-63)$.

MIP- $3 \alpha$ is an $8.0-\mathrm{kDa}$ CC chemokine that, in addition to being chemotactic for DCs, is chemotactic for lymphocytes but not for monocytes or neutrophils (35, 37). Immature DCs derived from CD34+ hematopoietic progenitor cells migrate vigorously in response to MIP-3 $\alpha$, but upon maturation, the DCs lose their response to this chemokine (64). Consistent with this observation, mRNA levels for CCR6 (the MIP-3 $\alpha$ receptor) are high in immature DCs and decrease as DC mature $(58,64-66)$. In normals, the MIP- $3 \alpha$ gene is expressed in liver, lung, and lymphoid tissue, as well as in activated endothelial cells and monocytes (35-38). Indirect evidence that MIP-3 $\alpha$ might attract DCs in vivo comes from studies showing MIP- $3 \alpha$ mRNA within inflamed epithelial crypts of tonsils (64).

Several cell lines express MIP- $3 \alpha$, and the production of MIP- $3 \alpha$ is induced by inflammatory stimuli such as LPS or TNF- $\alpha$ by endothelial cells and monocytes (35, $36)$. We could not detect MIP- $3 \alpha$ mRNA or protein in A549 cells without infection of AdMIP-3 $\alpha$, nor tumors in vivo. However, if MIP-3 $\alpha$ expression is induced at sites other than normal, MIP- $3 \alpha$ clearly can function to attract DCs to other sites, as we observed the increased number of DCs in tumors injected with AdMIP-3 $\alpha$.

Immunotherapy of tumors using DCs. In contrast to other strategies of activating DCs in vivo (such as intravenous administration of recombinant Flt3 ligand that systemically harvests DCs to differentiate from early hematopoietic precursor/stem cells, resulting in accumulation of DC in tumors and tumor regression [67-71]), the present study focuses on the accumulation of DCs only at the tumor site, where they participate in activating antigen-specific T-cell responses. A variety of strategies have been devised to use DCs to stimulate immunity against tumor antigens, including pulsing DCs with tumor-related peptides or apoptotic tumor cells, or genetically modifying DCs with total RNA from tumor cells, genes coding for tumor-related antigens, or genes that acti-

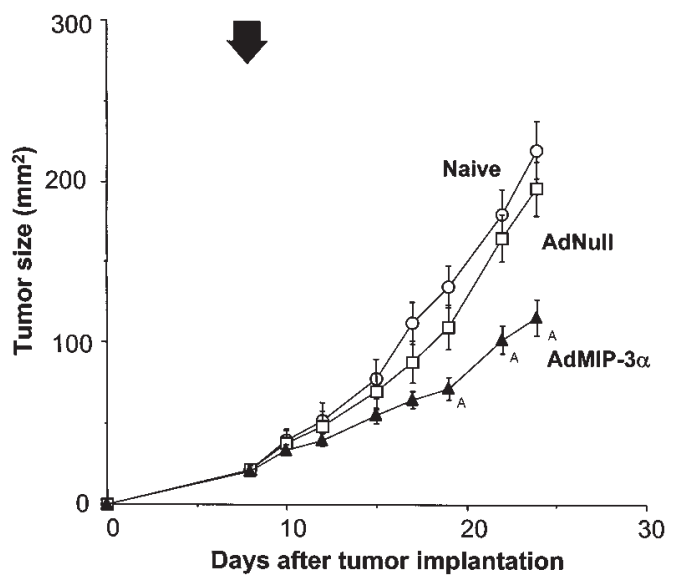


vate immune responses $(1,2,4-34)$. For all of these methods, there is a requirement for ex vivo manipulation to purify DCs and to bring the DCs and tumor cells/tumor antigens into contact $(1,2,11,14)$.

In contrast, the present study is directed toward evaluating a new paradigm of harnessing DCs to initiate antitumor immunity by using in vivo gene transfer to attract endogenous DCs to tumors. We hypothesized that if tumors could be genetically modified in vivo to produce MIP- $3 \alpha$, the consequences should be accumulation of DCs within the tumor, and the in vivo interaction of DCs with the tumor cells/tumor antigens should induce immunity against the tumor with consequent suppression of tumor growth. In this study, we demonstrated that local production of MIP- $3 \alpha$ by AdMIP- $3 \alpha$-transduced tumor cells could induce the local accumulation of DCs with a tumor-specific CTL response and inhibit the growth of tumors without ex vivo manipulation of DCs. This strategy may be useful in enlisting the help of DCs in boosting antitumor immunity for local and metastatic diseases.

\section{Acknowledgments}

We thank T. Kikuchi, N. Sato, N. Miyazawa, P.L. Leopold, and N.R. Hackett in our laboratory for help with these studies; and N. Mohamed for help in preparing this manuscript. These studies were supported, in part, by a grant from the National Institutes of Health (R01 CA75192); the Will Rogers Memorial Fund; and GenVec, Inc. M A.S. Moore was supported, in part, by a grant from the National Cancer Institute (NCI-P30-CA-08748) and the Gar Reichman Fund of the Cancer Research Institute.

1. Banchereau, J., and Steinman, R.M. 1998. Dendritic cells and the control of immunity. Nature. 392:245-252.

2. Timmerman, J.M. 1999. Dendritic cell vaccines for cancer immunotherapy. Annu. Rev. Med. 50:507-529.

3. Rissoan, M.C., et al. 1999. Reciprocal control of T helper cell and dendritic cell differentiation. Science. 283:1183-1186.

4. Albert, M.L., Sauter, B., and Bhardwaj, N. 1998. Dendritic cells acquire antigen from apoptotic cells and induce class I-restricted CTL. Nature. 392:86-89.

5. Ashley, D.M., et al. 1997. Bone marrow-generated dendritic cells pulsed with tumor extracts or tumor RNA induce antitumor immunity against central nervous system tumors. J. Exp. Med. 186:1177-1182.

6. Boczkowski, D., Nair, S.K., Snyder, D., and Gilboa, E. 1996. Dendritic cells pulsed with RNA are potent antigen-presenting cells in vitro and in vivo. J. Exp. Med. 184:465-472.

7. Brossart, P., Goldrath, A.W., Butz, E.A., Martin, S., and Bevan, M.J. 1997. Virus-mediated delivery of antigenic epitopes into dendritic cells as a means to induce CTL. J. Immunol. 158:3270-3276.

8. Celluzzi, C.M., Mayordomo, J.I., Storkus, W.J., Lotze, M.T., and Falo, L.D. 1996. Peptide-pulsed dendritic cells induce antigen-specific, CTLmediated protective tumor immunity. J. Exp. Med. 183:283-287.

9. Celluzzi, C.M., and Falo, L.D., Jr. 1998. Physical interaction between dendritic cells and tumor cells results in an immunogen that induces protective and therapeutic tumor rejection. J. Immunol. 160:3081-3085.

10. Henderson, R.A., et al. 1996. Human dendritic cells genetically engineered to express high levels of the human epithelial tumor antigen mucin (MUC-1). Cancer Res. 56:3763-3770.

11. Hsu, F.J., et al. 1996. Vaccination of patients with B-cell lymphoma using autologous antigen-pulsed dendritic cells. Nat. Med. 2:52-58.

12. Mayordomo, J.I., et al. 1995. Bone marrow-derived dendritic cells pulsed with synthetic tumour peptides elicit protective and therapeutic antitumour immunity. Nat. Med. 1:1297-1302.

13. Mayordomo, J.I., et al. 1996. Therapy of murine tumors with p53 wildtype and mutant sequence peptide-based vaccines. J. Exp. Med.
183:1357-1365.

14. Nestle, F.O., et al. 1998. Vaccination of melanoma patients with peptide- or tumor lysate-pulsed dendritic cells. Nat. Med. 4:328-332.

15. Paglia, P., Chiodoni, C., Rodolfo, M., and Colombo, M.P. 1996. Murine dendritic cells loaded in vitro with soluble protein prime cytotoxic $\mathrm{T}$ lymphocytes against tumor antigen in vivo. J. Exp. Med. 183:317-322.

16. Porgador, A., Snyder, D., and Gilboa, E. 1996. Induction of antitumor immunity using bone marrow-generated dendritic cells. J. Immunol. 156:2918-2926.

17. Reeves, M.E., Royal, R.E., Lam, J.S., Rosenberg, S.A., and Hwu, P. 1996. Retroviral transduction of human dendritic cells with a tumor-b associated antigen gene. Cancer Res. 56:5672-5677.

18. Ribas, A., et al. 1997. Genetic immunization for the melanoma antigen MART-1/Melan-A using recombinant adenovirus-transduced murine dendritic cells. Cancer Res. 57:2865-2869.

19. Schuler, G., Thurner, B., and Romani, N. 1997. Dendritic cells: from ignored cells to major players in T-cell-mediated immunity. Int. Arch. Allergy Immunol. 112:317-322.

20. Song, W., et al. 1997. Dendritic cells genetically modified with an adenovirus vector encoding the cDNA for a model antigen induce protective and therapeutic antitumor immunity. J. Exp. Med. 186:1247-1256.

21. Specht, J.M., et al. 1997. Dendritic cells retrovirally transduced with a model antigen gene are therapeutically effective against established pulmonary metastases. J. Exp. Med. 186:1213-1221.

22. Wan, Y., Bramson, J., Carter, R., Graham, F., and Gauldie, J. 1997. Dendritic cells transduced with an adenoviral vector encoding a model tumor-associated antigen for tumor vaccination. Hum. Gene Ther. 8:1355-1363.

23. Zitvogel, L., et al. 1996. Therapy of murine tumors with tumor peptidepulsed dendritic cells: dependence on T cells, B7 costimulation, and T helper cell 1-associated cytokines. J. Exp. Med. 183:87-97.

24. Bronte, V., et al. 1997. Antigen expression by dendritic cells correlates with the therapeutic effectiveness of a model recombinant poxvirus tumor vaccine. Proc. Natl. Acad. Sci. USA. 94:3183-3188.

25. De Veerman, M., et al. 1999. Retrovirally transduced bone marrowderived dendritic cells require $\mathrm{CD} 4+\mathrm{T}$ cell help to elicit protective and therapeutic antitumor immunity. J. Immunol. 162:144-151.

26. Fields, R.C., Shimizu, K., and Mule, J.J. 1998. Murine dendritic cells pulsed with whole tumor lysates mediate potent antitumor immune responses in vitro and in vivo. Proc. Natl. Acad. Sci. USA. 95:9482-9487.

27. Flamand, V., et al. 1994. Murine dendritic cells pulsed in vitro with tumor antigen induce tumor resistance in vivo. Eur. J. Immunol. 24:605-610.

28. Gong, J., et al. 1998. Reversal of tolerance to human MUC1 antigen in MUC1 transgenic mice immunized with fusions of dendritic and carcinoma cells. Proc. Natl. Acad. Sci. USA. 95:6279-6283.

29. Tuting, T., De Leo, A.B., Lotze, M.T., and Storkus, W.J. 1997. Genetically modified bone marrow-derived dendritic cells expressing tumorassociated viral or "self" antigens induce antitumor immunity in vivo. Eur. J. Immunol. 27:2702-2707.

30. Tuting, T., et al. 1998. Autologous human monocyte-derived dendritic cells genetically modified to express melanoma antigens elicit primary cytotoxic $\mathrm{T}$ cell responses in vitro: enhancement by cotransfection of genes encoding the Th1-biasing cytokines IL-12 and IFN- $\alpha$. J. Immunol. 160:1139-1147.

31. Wang, J., Saffold, S., Cao, X., Krauss, J., and Chen, W. 1998. Eliciting T cell immunity against poorly immunogenic tumors by immunization with dendritic cell-tumor fusion vaccines. J. Immunol. 161:5516-5524.

32. Gong, J. 1997. Induction of antigen-specific antitumor immunity with adenovirus-transduced dendritic cells. Gene Ther. 4:1023-1028.

33. Gong, J., Chen, D., Kashiwaba, M., and Kufe, D. 1997. Induction of antitumor activity by immunization with fusions of dendritic and carcinoma cells. Nat. Med. 3:558-561.

34. Cao, X., et al. 1998. Lymphotactin gene-modified bone marrow dendritic cells act as more potent adjuvants for peptide delivery to induce specific antitumor immunity. J. Immunol. 161:6238-6244.

35. Hieshima, K., et al. 1997. Molecular cloning of a novel human CC chemokine liver and activation-regulated chemokine (LARC) expressed n liver. Chemotactic activity for lymphocytes and gene localization on chromosome 2. J. Biol. Chem. 272:5846-5853.

36. Hromas, R., et al. 1997. Cloning and characterization of exodus, a novel $\beta$-chemokine. Blood. 89:3315-3322.

37. Power, C.A., et al. 1997. Cloning and characterization of a specific receptor for the novel CC chemokine MIP- $3 \alpha$ from lung dendritic cells. Exp. Med. 186:825-835.

38. Rossi, D.L., Vicari, A.P., Franz-Bacon, K., McClanahan, T.K., and Zlotnik, A. 1997. Identification through bioinformatics of two new macrophage proinflammatory human chemokines: MIP- $3 \alpha$ and MIP3a. J. Immunol. 158:1033-1036.

39. Rosenfeld, M.A., et al. 1991. Adenovirus-mediated transfer of a recombinant alpha 1-antitrypsin gene to the lung epithelium in vivo. Science. 
252:431-434

40. Rosenfeld, M.A., et al. 1992. In vivo transfer of the human cystic fibrosis transmembrane conductance regulator gene to the airway epithelium. Cell. 68:143-155.

41. Hersh, J., Crystal, R.G., and Bewig, B. 1995. Modulation of gene expression after replication-deficient, recombinant adenovirus-mediated gene transfer by the product of a second adenovirus vector. Gene Ther. 2:124-131.

42. Crystal, R.G., et al. 1994. Administration of an adenovirus containing the human CFTR cDNA to the respiratory tract of individuals with cystic fibrosis. Nat. Genet. 8:42-51.

43. Wang, M., et al. 1995. Active immunotherapy of cancer with a nonreplicating recombinant fowlpox virus encoding a model tumor-associated antigen. J. Immunol. 154:4685-4692.

44. Rawle, F.C., et al. 1991. Specificity of the mouse cytotoxic T lymphocyte response to adenovirus 5. E1a is immunodominant in $\mathrm{H}-2 \mathrm{~b}$, but not in $\mathrm{H}-2 \mathrm{~d}$ or $\mathrm{H}-2 \mathrm{k}$ mice. J. Immunol. 146:3977-3984.

45. Inaba, K., et al. 1992. Generation of large numbers of dendritic cells from mouse bone marrow cultures supplemented with granulocyte/macrophage colony-stimulating factor. J. Exp. Med. 176:1693-1702.

46. Falk, W., Goodwin, R.H.J., and Leonard, E.J. 1980. A 48-well micro chemotaxis assembly for rapid and accurate measurement of leukocyte migration. J. Immunol. Methods. 33:239-247.

47. Austyn, J.M., Kupiec-Weglinski, J.W., Hankins, D.F., and Morris, P.J. 1988. Migration patterns of dendritic cells in the mouse. Homing to $T$ cell-dependent areas of spleen, and binding within marginal zone. $J$. Exp. Med. 167:646-651.

48. Kupiec-Weglinski, J.W., Austyn, J.M., and Morris, P.J. 1988. Migration patterns of dendritic cells in the mouse. Traffic from the blood, and $\mathrm{T}$ cell-dependent and -independent entry to lymphoid tissues. J. Exp. Med. 167:632-645

49. Weinlich, G., et al. 1998. Entry into afferent lymphatics and maturation in situ of migrating murine cutaneous dendritic cells. J. Invest. Dermatol. 110:441-448.

50. Larsen, C.P., et al. 1990. Migration and maturation of Langerhans cells in skin transplants and explants. J. Exp. Med. 172:1483-1493.

51. Cumberbatch, M., and Kimber, I. 1995. Tumour necrosis factor- $\alpha$ is required for accumulation of dendritic cells in draining lymph nodes and for optimal contact sensitization. Immunology. 84:31-35.

52. Cumberbatch, M., Dearman, R.J., and Kimber, I. 1997. Langerhans cells require signals from both tumour necrosis factor- $\alpha$ and interleukin- 1 $\beta$ for migration. Immunology. 92:388-395.

53. Lee, C.T., et al. 1997. Genetic immunotherapy of established tumors with adenovirus-murine granulocyte-macrophage colony-stimulating factor. Hum. Gene Ther. 8:187-193.

54. Roake, J.A., et al. 1995. Dendritic cell loss from nonlymphoid tissues after systemic administration of lipopolysaccharide, tumor necrosis factor, and interleukin 1. J. Exp. Med. 181:2237-2247.

55. De Smedt, T., et al. 1996. Regulation of dendritic cell numbers and maturation by lipopolysaccharide in vivo. J. Exp. Med. 184:1413-1424.

56. Kaplan, G., et al. 1992. Novel responses of human skin to intradermal recombinant granulocyte/macrophage-colony-stimulating factor: Langerhans cell recruitment, keratinocyte growth, and enhanced wound healing. J. Exp. Med. 175:1717-1728.

57. MacPherson, G.G., Jenkins, C.D., Stein, M.J., and Edwards, C. 1995 Endotoxin-mediated dendritic cell release from the intestine. Characterization of released dendritic cells and TNF dependence. J. Immunol. 154:1317-1322.

58. Greaves, D.R., et al. 1997. CCR6, a CC chemokine receptor that interacts with macrophage inflammatory protein $3 \alpha$ and is highly expressed in human dendritic cells. J. Exp. Med. 186:837-844.

59. Morelli, A., Larregina, A., Chuluyan, I., Kolkowski, E., and Fainboim, L. 1996. Expression and modulation of C5a receptor (CD88) on skin dendritic cells. Chemotactic effect of $\mathrm{C} 5 \mathrm{a}$ on skin migratory dendritic cells. Immunology. 89:126-134.

60. Sozzani, S., et al. 1995. Migration of dendritic cells in response to formyl peptides, C5a, and a distinct set of chemokines. J. Immunol. 155:3292-3295.

61. Sozzani, S., et al. 1997. Receptor expression and responsiveness of human dendritic cells to a defined set of CC and CXC chemokines. $J$. Immunol. 159:1993-2000.

62. Godiska, R., et al. 1997. Human macrophage-derived chemokine (MDC), a novel chemoattractant for monocytes, monocyte-derived dendritic cells, and natural killer cells. J. Exp. Med. 185:1595-1604.

63. Xu, L.L., Warren, M.K., Rose, W.L., Gong, W., and Wang, J.M. 1996 Human recombinant monocyte chemotactic protein and other C-C chemokines bind and induce directional migration of dendritic cells in vitro. J. Leukoc. Biol. 60:365-371.

64. Dieu, M.C., et al. 1998. Selective recruitment of immature and mature dendritic cells by distinct chemokines expressed in different anatomic sites. J. Exp. Med. 188:373-386.

65. Baba, M., et al. 1997. Identification of CCR6, the specific receptor for a novel lymphocyte-directed CC chemokine LARC. J. Biol. Chem. 272:14893-14898.

66. Liao, F., et al. 1997. STRL22 is a receptor for the CC chemokine MIP$3 \alpha$. Biochem. Biophys. Res. Commun. 236:212-217.

67. Chen, K., et al. 1997. Antitumor activity and immunotherapeutic properties of Flt3-ligand in a murine breast cancer model. Cancer Res. 57:3511-3516.

68. Lynch, D.H., et al. 1997. Flt3 ligand induces tumor regression and antitumor immune responses in vivo. Nat. Med. 3:625-631.

69. Maraskovsky, E., et al. 1996. Dramatic increase in the numbers of functionally mature dendritic cells in Flt3 ligand-treated mice: multiple dendritic cell subpopulations identified. J. Exp. Med. 184:1953-1962.

70. Shurin, M.R., et al. 1997. FLT3 ligand induces the generation of functionally active dendritic cells in mice. Cell Immunol. 179:174-184.

71. Esche, C., Subbotin, V.M., Maliszewski, C., Lotze, M.T., and Shurin, M.R. 1998. FLT3 ligand administration inhibits tumor growth in murine melanoma and lymphoma. Cancer Res. 58:380-383. 